\title{
Siew New Disease Reports \\ First report of anthracnose of elephant foot yam caused by Colletotrichum siamense in India
}

\author{
L. Prasad ${ }^{1}$, S. Javeria ${ }^{1}$, B. Kumar ${ }^{2}$ and P. Sharma ${ }^{1}$ \\ ${ }^{1}$ Division of Plant Pathology, Indian Agricultural Research Institute, New Delhi, 110012, India; ${ }^{2}$ Departments of Plant \\ Pathology, College of Agriculture, G.B. Pant University of Agriculture and Technology, Pantnagar-263145, Uttarakhand, \\ India
}

*E-mail: laxmanprasad25@yahoo.com

Received: 30 Oct 2017. Published: 27 Nov 2017. Keywords: fungal plant disease, vegetable crop

Elephant foot yam (Amorphophallus paeoniifolius) is an important aroid vegetable tuber crop in tropical/sub-tropical areas and is also used as medicine. Elephant foot yam plants exhibiting pale to tan spots on leaves were observed (Fig 1) at the Vegetable Research Centre, G.B. Pant University of Agriculture and Technology, Pantnagar, and kitchen gardens in New Delhi, India. To isolate the causal agent, small pieces (3-4 $\mathrm{mm}$ ) of diseased leaves were surface sterilised with $1 \% \mathrm{NaOCl}$ for three minutes, and subsequently washed thrice in steriled water and placed on potato dextrose agar (PDA) medium at $25^{\circ} \mathrm{C}$ for five days. The fungus was recovered from all infected samples. All four morphologically similar isolates were purified by single spore culturing and subcultured on PDA at $25^{\circ} \mathrm{C}$ for seven days. The shape and size of fifty conidia were determined by microscopy. Single spore colonies grown on PDA at $27 \pm 1^{\circ} \mathrm{C}$ were at first white and later became pale brownish to pinkish, reverse pale yellowish to pinkish colonies. Mycelia were greyish-white, dense, cottony, with visible conidial masses. Acervuli brown to dark brown, conspicuous for their brown setae. Conidia 8-17.2 × 3-4 $\mu$ m, one-celled, smooth-walled, guttulate, hyaline, fusiform with obtuse to slightly rounded ends, sometimes oblong. Based on morphology, the fungus was identified as Colletotrichum siamense Prihastuti, L. Cai \& K.D. Hyde (Prihastuti et al., 2009).

Pathogenicity was confirmed using the method of Watanabe et al. (2015) where four-month old healthy plant leaves of elephant foot yam using both the pin-prick and non-pin-prick methods. Both sets were inoculated with a disc $(6 \mathrm{~mm})$ of a four-day old culture of fungus mycelia applied to the host. Control sets of leaves were inoculated with sterile PDA discs with three replications. All treatments were incubated in a greenhouse under natural daylight conditions at $27 \pm 1^{\circ} \mathrm{C}$ on water agar and the petiole part of the leaves covered by a $2 \%$ sucrose-moistened cotton plug. Observations were made every 24 hours for the appearance or absence of leaf spots. Disease symptoms on leaves were observed in all $C$. siamense-inoculated leaves on the second day on pin-prick and on the fourth day on non-pin-prick plants, while no symptoms were observed in controls. Fungus was consistently reisolated and found to be identical to the original isolates, which confirmed the pathogenicity of $C$. siamense on elephant foot yam. Infections on leaves were very severe with a circular to crescent shape and tan to dark brown spots. The spots frequently coalesced into extended patches blighting the leaves and gradually the entire foliage. Brown lesions containing dark spore- producing bodies on leaves, and later lesions were enlarged and coalesced to kill the entire leaf.

Genomic DNA was extracted from mycelia of the isolated fungus using the CTAB method (Doyle \& Doyle, 1990) and the internal transcribed spacer (ITS) region of rDNA was amplified using primers ITS1 and ITS4 (White et al., 1990). A PCR product of the predicted size (556 bp) was amplified from the 5.8S rDNA region from all four isolates. A representative PCR product of one isolate was sequenced and submitted to GenBank (Accession No. KY887026) which had 85\% identity with a Chinese isolate of $C$. siamense (KP703364). A pure culture of $C$. siamense was deposited in the Indian Type Culture Collection IARI, New Delhi (ITCC No.8179).

Based on the cultural, morphological, pathogenicity, and molecular characteristics of the fungus obtained from elephant foot yam was identified as $C$. siamense. This is the first report of leaf spot caused by $C$. siamense on elephant foot yam in India or globally. It will be important to develop effective means to disease control.

\section{Acknowledgements}

The authors acknowledge the ICAR and the Director, ICAR-Indian Agricultural Research Institute, New Delhi, India for providing research facilities.

\section{References}

Doyle JJ, Doyle JL, 1990. A rapid total DNA preparation procedure for fresh plant tissue. Focus 12, 13-15.

Prihastuti H, Cai L, Chen H, McKenzie EHC, Hyde KD, 2009.

Characterization of Colletotrichum species associated with coffee berries in northern Thailand. Fungal Diversity 39, 89-109.

Watanabe K, Ikeda H, Sakashita T, Sato T, 2015. Anthracnose of genus Mandevilla caused by Colletotrichum truncatum and C. siamense in Japan. Journal of General Plant Pathology 82, 33-37. http://dx.doi.org/10.1007/s10327-015-0635-6

White TJ, Bruns T, Lee S, Taylor J, 1990. Amplification and direct sequencing of fungal ribosomal genes for phylogenetics. In: Innis MA, Gelfand DH, Shinsky J, White TJ, eds. PCR Protocols. A Guide to methods and Applications. San Diego, CA, USA: Academic Press, 315-322.

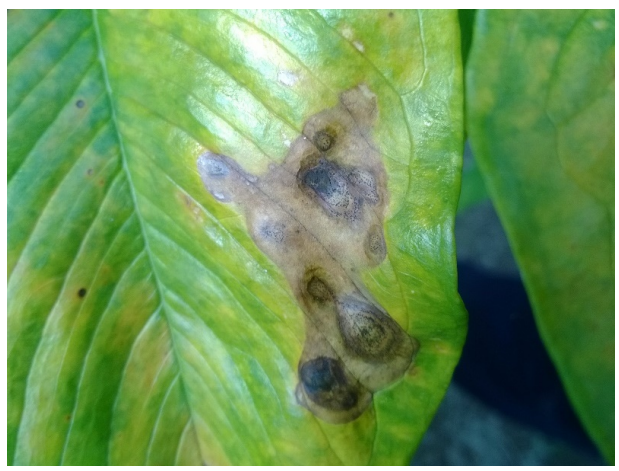

Figure 1

To cite this report: Prasad L, Javeria S, Kumar B, Sharma P, 2017. First report of anthracnose of elephant foot yam caused by Colletotrichum siamense in India. New Disease Reports 36, 21. http://dx.doi.org/10.5197/j.2044-0588.2017.036.021 